\title{
Placement of Distributed Generation and Shunt Capacitor in Distribution Network using Cuckoo Search Algorithm
}

\author{
Moses Uchendu* \\ Department of Electrical Engineering, Ahmadu Bello University Zaria, Nigeria.
}

\begin{abstract}
This work aims at reduction in active and reactive power loss reduction in distribution networks as well as to improve the voltage stability of the networks. Optimum Distributed Generation (DG) placement and sizing is carried out in conjunction with shunt capacitor placement and sizing to determine the appropriate sizes of DG units and Capacitor banks to be placed in the networks so as not to violate certain constraints. The optimal sizes of the DG units and capacitor banks were obtained on application of a Cuckoo Search Optimization Algorithm while computations for Voltage stability was performed using the Voltage Stability Index (VSI). The obtained optimal sizes of DG units and Capacitors were individually and simultaneously placed on the distribution networks to ascertain the behaviour of the networks prior to and after their placements. The performance factors considered are power loss and voltage stability. A comparison of these performance factors under separate and simultaneous placement method was demonstrated using IEEE 33 and 69 test buses. Result show that power loss (active and reactive) reduced by $63.29 \%$ and $59.38 \%$ respectively for 33 bus system, with a $74.29 \%$ and $79.19 \%$ reduction on 69 bus system. Voltage stability also increased by $7.89 \%$ and $3.79 \%$ respectively for 33 and 69 bus system relative to values obtained for base case and separate DG and shunt capacitor placement.
\end{abstract}

KEYWORDS: Distributed generation, shunt capacitor, Cuckoo Search Algorithm (CSA), power loss and voltage stability.

\section{INTRODUCTION}

An electrical distribution system (DS) is the last stage of electrical energy supply chain in power system operation whereby electricity is being distributed to individual customers through a radial network. With the advent of restructuring in power system operation and planning, many power companies are investing in small scale distributed power generation (Ackerman et al, 2001). Distributed Generation (DG) come in many different sizes and types raging from fractions of kilowatts to megawatts from the conventional combustion generating systems operated with the use of non- renewable energy sources to the non-conventional renewable energy generating systems such as wind turbines, photovoltaic (PV) cells, micro turbines and small hydro turbines.

A Distributed generation (DG) is an electric power source connected directly to the distribution network or on the consumer side of the meter" (Ackerman et al, 2001). Distributed Generation (DG) has many advantages over centralized power generation such as reduced transmission and distribution cost, power loss reduction and voltage profile improvement. An optimum DG placement and sizing at planning stage of distribution system is necessary to achieve maximum operation and benefits. Non - optimum
DG placement and sizing result to an increase in power loss and consequently lowers the voltage profile of power networks below the allowable limits (Aman et al, 2013).

The increment in active power loss represents loss in savings to a utility as well as a reduction in feeder utilization. Studies have shown that $70 \%$ of power losses occur at the distribution level Lund, T. (2007), and these losses can be categorized as technical (i.e. losses from overloading of lines, poor power factor) and non-technical losses (i.e. losses from defective meters, wrong tariffs).These losses have direct impact on the financial results and the overall efficiency of the system. When renewable energy - based DG units are placed for loss reduction, both aspects of energy sustainability, i.e., renewable energy and energy efficiency are addressed.

The challenges in DG applications for loss reduction are proper location, appropriate sizing, and operating strategies. In situations where a location is fixed, due to some other reasons, improper sizing would increase the losses in the system beyond that obtained without the DG (Hung et al., 2014). An optimum placement and sizingof DG is needed in order to minimize overall system losses and therefore improve voltage profiles of networks (El- Khattam and Salma, 2004). 
Drawing maximum active power from a utility in order to maximize profit from electricity sales usually leads to deficiency in reactive load requirements. The in - balance generated between the active power generated and consumed to the reactive power generated and consumed results in voltage instabilities and voltage collapse conditions in critical cases. Shunt capacitors optimal placement and sizing helps in power factor correction, thus improving the low power factor usually associated with inductive loads that lead to increased power losses and voltage instabilities. The stability of voltage can be maintained by providing reactive power support to the distribution systems at optimum locations Sumit, et al., (2010).

Considering the advantages of using both DGs and capacitors in distribution networks many researchers have recently proposed different techniques to simultaneously determine the locations and sizes of both to improve voltage stabilization and power loss minimization. Aman, et al., (2013) used the PSO algorithm to find the optimal location and size of shunt capacitor and DG in 12,30, 33 and 69- bus IEEE standard networks in order to minimize losses. The IEEE 33- bus network was employed as a test system in Esmaeilian, et al., (2014) to show the advantages in the use of Genetic Algorithm for locating DG and Capacitor.

The same purpose was followed in Kowsalya, M. (2014) where BFOA was applied to a 33- bus network, and the results are compared for three different cases of when: 1only DG, 2- both DG and capacitor, and 3- none of them, are used on the test system. Rahiminejad, et al., (2014) employed TLBO technique to maximize the ratio of the profit to cost when both capacitor and DG are used .In this paper, the above problem is solved by simultaneous DG and capacitor placement in a distribution system, with a view to minimization of power losses, voltage profile improvement and voltage stability improvement as performance factors.

This paper is organized as follows: Section 2 presents the proposed problem formulation. Section 3 presents a brief discussion on the cuckoo search optimization (CSA) algorithm. Section4 presents numerical results of the application of the proposed method on two test systems, observations and discussions. Finally, drawn conclusions are summarized in section 5 .

\section{FORMULATION OF THE PROBLEM}

In the proposed algorithm for simultaneous DG and capacitor placement, the objective function is defined as minimization of total active $\left(P_{L}\right)$ and reactive $\left(Q_{L}\right)$ power loss and VSI improvement.

$$
\operatorname{Min} f=f_{1}+f_{2}
$$

where $f_{1}$ is the total real power loss, while is $f_{2}$ is the voltage stability index (VSI).

In this study, the total real and reactive power losses are selected as one of the objective functions, which is expressed as the sum of all node injections of power in the distribution system. The first objective function, formulated as power loss indices is given by:

$$
f_{1}=\frac{P_{L D G}+Q_{L C B}}{P_{L}+Q_{L}}
$$

where $P_{L}$ and $Q_{L}$ are the total real and reactive power losses of the distribution system before the installation of DG and CB and $P_{L D G}$ and $Q_{L C B}$ are the real and reactive power losses after the installation of $\mathrm{DG}$ and $\mathrm{CB}$ respectively, and expressed as:

$$
P_{L(D G)}+Q_{L(C B)}=\sum_{n i=1}^{N} I_{n i}{ }^{2} R_{n i}
$$

In a radial distribution system, each receiving node is supplied by one sending node. When DG and CB is connected to the distribution network, the voltage stability index (VSI) which is presented by Charkravorty and Das, (2001) will be changed. Equations used to formulate this index are presented to solve the load flow for radial distribution systems. By using Eq. (4) and Eq. (5), Eq.(6) which represents the VSI is formulated as:

$I_{n i}=\frac{V_{m i}-V_{n i}}{R_{n i}+j X_{n i}}$

$P_{n i}(n i)-j Q_{n i}(n i)=V_{n i}^{*} I_{n i}$

$V S I_{(n i)}=\left|V_{m i}\right|^{4}-4\left[P_{n i}(n i) R_{n i}+Q_{n i}(n i) X_{n i}\right]\left|V_{m i}\right|^{2}$

$-4\left[P_{n i}(n i) R_{n i}+Q_{n i}(n i) X_{n i}\right]^{2}$

where $V_{m i}$, is the sending node voltage; while $V_{n i}, P_{n i}$, $Q_{n i}, R_{n i}$, and $X_{n i}$ are voltage, real power, reactive power, resistance and reactance for the receiving node.

The index is modified to become an objective function for improving VSI, as follows:

$$
f_{2}=\frac{1}{\min (\operatorname{VSI}(n i))} n_{i}=2,3,---, n_{n}
$$

where VSI $(n i)>0$ for $\mathrm{i}=2,3 \ldots \mathrm{n}$, so that a feasible solution exists. It is therefore very essential to recognize 
weak buses for nodes with minimum VSI that are disposed to voltage instability. Inspecting the VSI performance exposes that the buses which undergo huge voltage drops are weak and within the condition of corrective actions.

where:

$I$ is the current in branch $i$

$R$ is the resistance of branch $i$

$N$ is the total number of branches.

Eqn (7) is subject to the following constraints:

$i$. Power balance constraint

$$
\begin{gathered}
P_{S U B}+\sum_{i=1}^{n} P_{D G, i}=\sum_{i=1}^{n} P_{L, i}+P_{T, L O S S} \\
Q_{\text {sub }}+\sum_{i=1}^{n} Q_{D G i}+\sum_{i=1}^{n} Q_{\text {Capi }}=\sum_{i=1}^{n} Q_{L i}+Q_{T, L o s s} \\
\text { ii. } \quad \text { Voltage limits } \\
V_{i}^{\min } \leq V_{i} \leq V_{i}^{\max } \\
0.95 \leq V_{i} \leq 1.05
\end{gathered}
$$

iii. Power limits of the DGs

$P_{D G, i}{ }^{\min } \leq P_{D G, i} \leq P_{D G, i}{ }^{\max }$

where

$V_{b u s}$ is $n^{\text {th }}$ bus voltage.

\section{CUCKOO SEARCH OPTIMIZATION ALGORITHM}

Cuckoo Search Optimization (CSA) was introduced by Yang, X.-S. (2010) to solve the optimization problem, based on brood parasitic behaviour of some cuckoo species in combination with levy flight behaviour of fruit flies. CSA has two main operators; one of which is direct search based on levy flights and random search based on the probability of a host bird to discover an alien egg in its nest.

CSA consists of three steps:

i. Every cuckoo lays one egg at a time, and dumps its egg in a randomly chosen nest.

ii. The best nest with high quality eggs will carry over to the next generation

iii. The number of available host nests is fixed, and the egg laid by a cuckoo is discovered by the host bird with a probability $P_{a} \in[0,1]$.
When generating new solutions $x^{(t+1)}$ for a cuckoo $i$, a Levy flight is performed

$$
x_{i}^{(t+1)}=x_{i}^{(t)}+\alpha \oplus \operatorname{Levy}(\lambda)
$$

where $\alpha>0$ is the step size, which should be related to the scale of the problem of concern. The product $\oplus$ means an entry - wise multiplications. According to Yang (2010), levy flights essentially provide a random walk while their random steps are drawn from a levy distribution for large steps.

Levy $\approx u=t^{-\lambda}, 1<\lambda \leq 3$

Here, the consecutive steps of a cuckoo essentially from a random walk process with a power law step length distribution with a heavy tail (Yang, 2010). Numerous new solutions should be generated by levy walk near the best solution obtained, since this process will speed up the local exploration.

In the present case of DG placement and sizing, the $i^{\text {th }}$ particle $\left(x_{i}\right)$ is a four dimension vector $\left(P_{D G}, i, P_{D G}, Q_{\text {shunt }, i}\right.$, $Q_{\text {shunt }}$ ), representing random DG and shunt capacitor positions $\left(P_{D G, i}\right.$ and $\left.Q_{\text {shunt }, i}\right)$ and DG and shunt capacitor sizes $\left(P_{D G}\right.$ and $\left.Q_{\text {shunt }}\right)$.

\section{A. Cuckoo Search for Distributed Generation Placement}

The implementation CS for optimal sizing and sizing of DG and capacitor bank problem entailed the determination of several steps of procedure as represented in Table 1. For CS parameter settings number of nests, $\mathrm{n}=25$, step size, $\alpha=1$ and the probability to discover foreign eggs $P_{a}=0.6$ have been applied in this study. On the other hand, network topology based on forward/ backward sweep algorithm was used for load flow analysis to evaluate the objective function, owing to its robust convergence characteristics, effectiveness in handling uncertainties of network parameters and computational effectiveness

Table 1 shows the complete steps of the proposed algorithm for optimal DG and shunt capacitor placement and sizing. Forward- Backward sweep load flow technique was used to carry out the load flow analysis.

Step 1: Initialize population.

The CS must be provided with the population number, $\mathrm{n}$ and the initial range of host nests at the start, which can be specified by the user. If the user does not suggest an initial range, the algorithm will create an initial population with the default value. The initial population will be evaluated 
using the objective function, which is the driving force behind CS.

\section{Step 2: Generation of cuckoo.}

The cuckoo is randomly generated by levy flight. The cuckoo is evaluated using the load flow and objective functions $\left(f_{i}\right.$ and $f_{2}$ ) considering the constraints given in (8) - (11) in order to determine the quality of solution.

Step 3: To update initial position and generate new nets.

- Update cuckoos position using (12)

- Choose a nest among n (say $j$ ) randomly, calculate fitness $f_{j}$

- If $f_{j}>f_{i}$

- Replace better quality cuckoo to a nest via randomization

- Abandon a fraction $p_{a}$,of worst nests and build new ones at new locations via Levy flights

\section{Step 4: Termination}

In this study, the stopping criterion is set to a tolerance value of $1 e^{-6}$ and maximum generation of 100 iterations. After satisfied the stopping criterion, the iteration will be stopped and the result of CS will be obtained.

\section{B. Computational Procedure}

The computational procedure to find the optimal size and location of the renewable energy - based DG units and shunt capacitor banks is described as follows;

Step 1: Run load flow for the base case.

Step 2: Find the base case loss using (3).

Step 3: Find the optimal sizes of DG and CB for each bus using (11).

Step 4: Place DGs and CBs with the optimal sizes obtained in step 3 at each bus, one at a time. Calculate the approximate losses for each case using (2).

Step 5: Locate and record values of buses at which the total loss is minimal corresponding with the optimal sizes at that bus.

Step 6: Run load flow and calculate for VSI values at each bus.

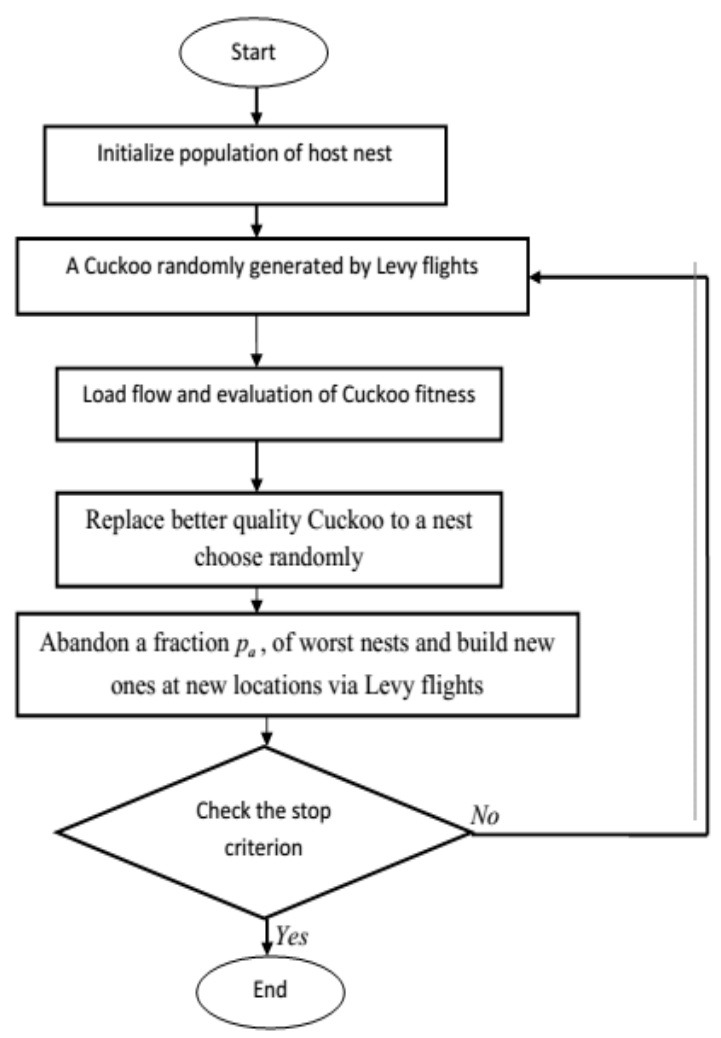

Figure 1: Cuckoo Search Algorithm (Yang and Deb, 2009).

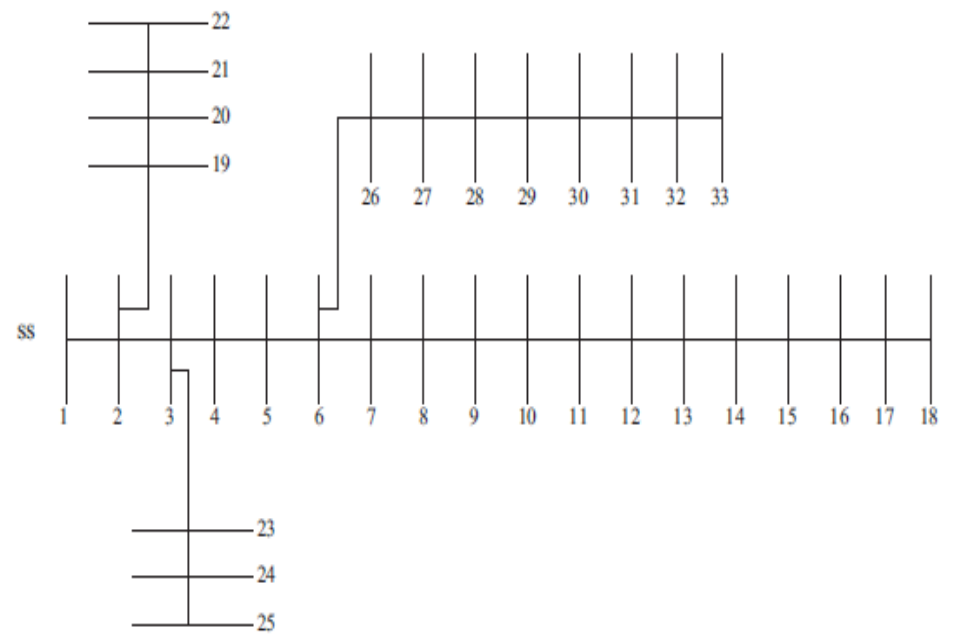

Figure 2: Single line diagram of 33 bus radial distribution network (Yuvaraj et al., 2015). 


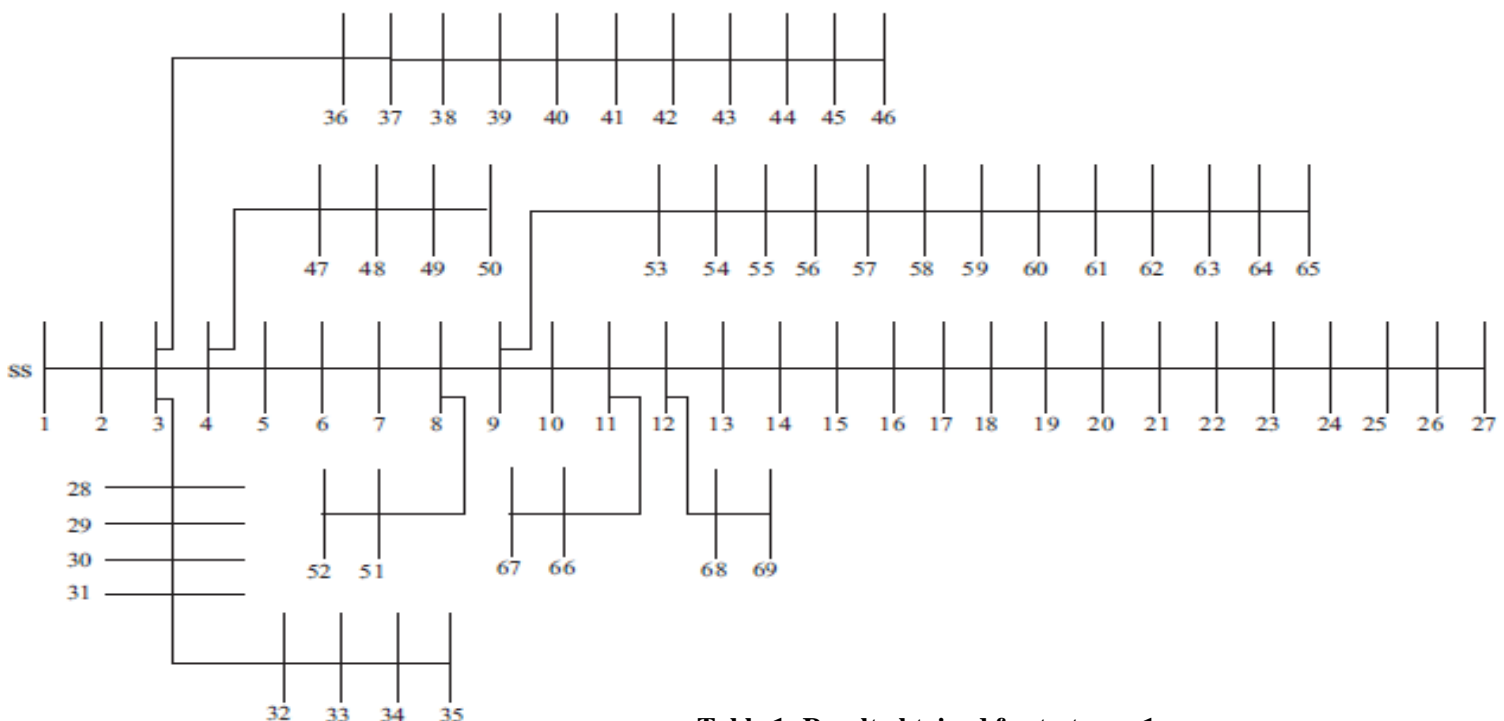

Figure 3: Single line diagram of 69 bus radial distribution network (Yuvaraj et al., 2015).

\section{SIMULATION RESULTS}

The proposed algorithm was tested on 33-bus (Yuvaraj et al., 2015) and 69-bus (Yuvaraj et al., 2015) radial distribution systems as illustrated in Figures 1and 2. The power of all network buses are assumed to be delivered by the substation placed at node 1 . The total real and reactive power loads for the 33 and 69 bus radial distribution systems are $3.72 \mathrm{MW}, 2.3$ MVar and 3.80 MW, 2.69 MVar respectively. The objective function values before installation of $\mathrm{DG}$ and $\mathrm{CB}$, which include the total power loads and VSI values, are $79 \mathrm{~kW}, 64$ $\mathrm{kVar}$ for real and reactive power for 33 bus system and $70 \mathrm{~kW}$, $48 \mathrm{kVar}$ for real and reactive power for 69 bus system. Base case VSI values for 33 and 69 bus system are 0.5758 and 0.6146

In order to directly obtain the optimal sizing and siting of DGs and $\mathrm{CBs}$ in the distribution system with the target of minimizing the total real power losses and improving the voltage stability while maintaining the acceptable voltage limit, the cuckoo search algorithm was used, which is a selfdeveloping code, built using Matlab script functions.

\section{A. Presentation of Results}

The results obtained for power loss reduction in the three test cases of DG and CB placement in a radial distribution network as considered in this research work are presented in Table 1, Table 2 and Table 3 respectively, while results for voltage stability improvement profile, active and reactive power loss profile, voltage improvement profile are presented with figures.

Table 1: Result obtained for test case 1.

\begin{tabular}{|c|c|c|c|c|c|c|c|}
\hline \multirow[t]{2}{*}{$\begin{array}{c}\text { Test } \\
\text { system }\end{array}$} & \multirow[t]{2}{*}{$\begin{array}{l}\text { Bus } \\
\text { no. }\end{array}$} & \multirow[t]{2}{*}{$\begin{array}{l}\text { SC size } \\
(\mathrm{kVar})\end{array}$} & \multicolumn{2}{|c|}{ Power Loss } & \multicolumn{2}{|c|}{$\begin{array}{c}\text { Loss Reduction } \\
(\%)\end{array}$} & \multirow[t]{2}{*}{$\begin{array}{l}\text { Max } \\
\text { (VSI) }\end{array}$} \\
\hline & & & $\begin{array}{c}P_{L} \\
(\mathbf{k W})\end{array}$ & $\underset{(\mathbf{k V a r})}{Q_{L}}$ & $P_{L}$ & $Q_{L}$ & \\
\hline 33 bus & $\begin{array}{l}30, \\
25, \\
24\end{array}$ & $\begin{array}{l}620.18, \\
198.98, \\
188.29\end{array}$ & 37 & 30 & 53.16 & 53.13 & 0.6292 \\
\hline 69 bus & $\begin{array}{l}56, \\
39, \\
12\end{array}$ & $\begin{array}{l}873.64, \\
330.85, \\
105.67\end{array}$ & 50 & 33 & 28.57 & 31.25 & 0.7225 \\
\hline
\end{tabular}

Table 2: Result obtained for test case 2.

\begin{tabular}{|c|c|c|c|c|c|c|c|}
\hline \multirow[t]{2}{*}{$\begin{array}{c}\text { Test } \\
\text { system }\end{array}$} & \multirow[t]{2}{*}{$\begin{array}{l}\text { Bus } \\
\text { no. }\end{array}$} & \multirow[t]{2}{*}{$\begin{array}{c}\text { SC size } \\
\text { (kVar) }\end{array}$} & \multicolumn{2}{|c|}{ Power Loss } & \multicolumn{2}{|c|}{$\begin{array}{c}\text { Loss Reduction } \\
(\%)\end{array}$} & \multirow[t]{2}{*}{$\begin{array}{c}\text { Max } \\
\text { (VSI) }\end{array}$} \\
\hline & & & $\begin{array}{c}P_{L} \\
(\mathbf{k W})\end{array}$ & $\begin{array}{c}Q_{L} \\
(\mathbf{k V a r})\end{array}$ & $P_{L}$ & $Q_{L}$ & \\
\hline 33 bus & $\begin{array}{l}25, \\
30, \\
29\end{array}$ & $\begin{array}{l}501.89, \\
100.73, \\
179.47\end{array}$ & 54 & 44 & 31.65 & 31.25 & 0.6381 \\
\hline 69 bus & $\begin{array}{l}50, \\
53, \\
30\end{array}$ & $\begin{array}{l}131.82, \\
171.46, \\
677.89\end{array}$ & 34 & 22 & 51.43 & 54.17 & 0.9465 \\
\hline
\end{tabular}

\section{B. Discussion of Results}

\section{1.) Power loss reduction profile for test cases 1, 2 and 3}

Power loss reduction (active and reactive) performance test was carried out with different sizes of shunt capacitor banks and Distributed generations placed on IEEE 33 and 69 bus systems. Results showed that on placement of the sizes of shunt capacitor banks there was a reduction in active and reactive power losses in the test systems from their respective base case values. For test case 1, the active and reactive power loss reduced to $37 \mathrm{~kW}$ and $30 \mathrm{kVar}$ respectively for the 33 bus system and to $50 \mathrm{~kW}$ and $33 \mathrm{kVAr}$ respectively for the 69 bus system. 
Table 3: Result obtained for test case 3.

\begin{tabular}{|c|c|c|c|c|c|c|c|c|}
\hline \multirow[t]{2}{*}{$\begin{array}{c}\text { Test } \\
\text { system }\end{array}$} & \multirow[t]{2}{*}{$\begin{array}{l}\text { Bus } \\
\text { no. }\end{array}$} & \multicolumn{2}{|l|}{ Size } & \multicolumn{2}{|c|}{ Power Loss } & \multicolumn{2}{|c|}{$\begin{array}{c}\text { Loss Reduction } \\
(\%)\end{array}$} & \multirow[t]{2}{*}{$\begin{array}{l}\text { Max } \\
\text { (VSI) }\end{array}$} \\
\hline & & DG (kW) & SC (kVar) & $\begin{array}{c}P_{L} \\
(\mathbf{k W})\end{array}$ & $\begin{array}{c}Q_{L} \\
(\mathbf{k V a r})\end{array}$ & $P_{L}$ & $Q_{L}$ & \\
\hline 33 bus & $\begin{array}{l}35 \\
32 \\
30\end{array}$ & $\begin{array}{l}515.69, \\
214.01\end{array}$ & 572.27 & 29 & 24 & 63.29 & 59.38 & 0.6618 \\
\hline 69 bus & $\begin{array}{l}30, \\
50, \\
50\end{array}$ & $\begin{array}{l}239.83 \\
1408.79\end{array}$ & 885.58 & 18 & 10 & 74.29 & 79.17 & 1.0246 \\
\hline
\end{tabular}

For test case 2, the active and reactive power loss reduced to $54 \mathrm{~kW}$ and $44 \mathrm{kVAr}$ respectively for 33 bus system and to $34 \mathrm{~kW}$ and $22 \mathrm{kVAr}$ respectively for the 69 bus system. For test case 3 , the active and reactive power loss reduced to 29 $\mathrm{kW}$ and $24 \mathrm{kVAr}$ respectively for the 33 bus system and to 18 $\mathrm{kW}$ and $10 \mathrm{kVAr}$ respectively for the 69 bus system. The improvement obtained in the voltage stability profile for Test case 1, 2 and 3 respectively o IEEE 33 and 69 bus system is presented in Figures.

\section{2.) Voltage stability improvement for test cases 1, 2 and 3}

The voltage stability improvement profile for test case 1, 2 and 3 was also obtained via comparison with the base case voltage stability values obtained for IEEE 33 and 69 bus system. The profiles are shown in Figures $4-9$.

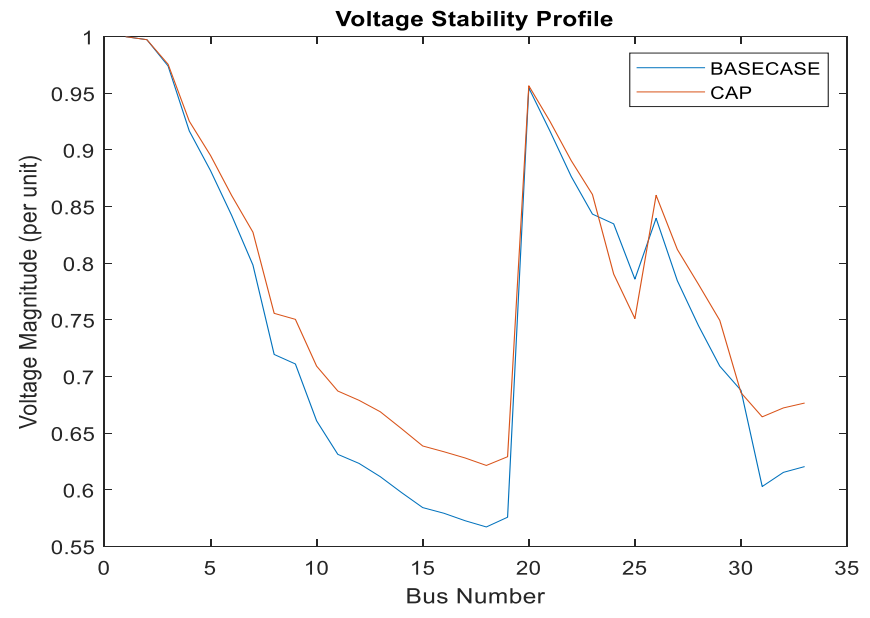

Figure 4: Voltage stability profile for test case 1 for 33 bus system.

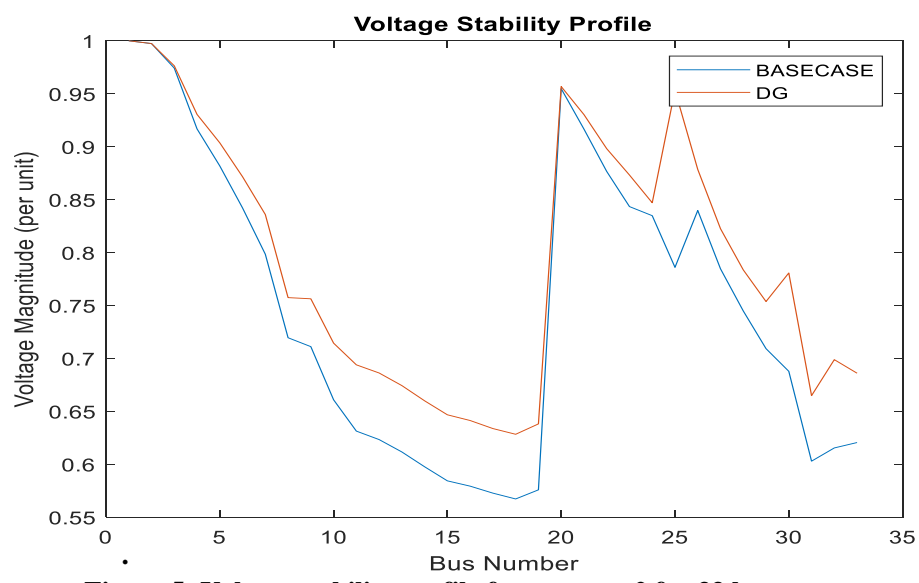

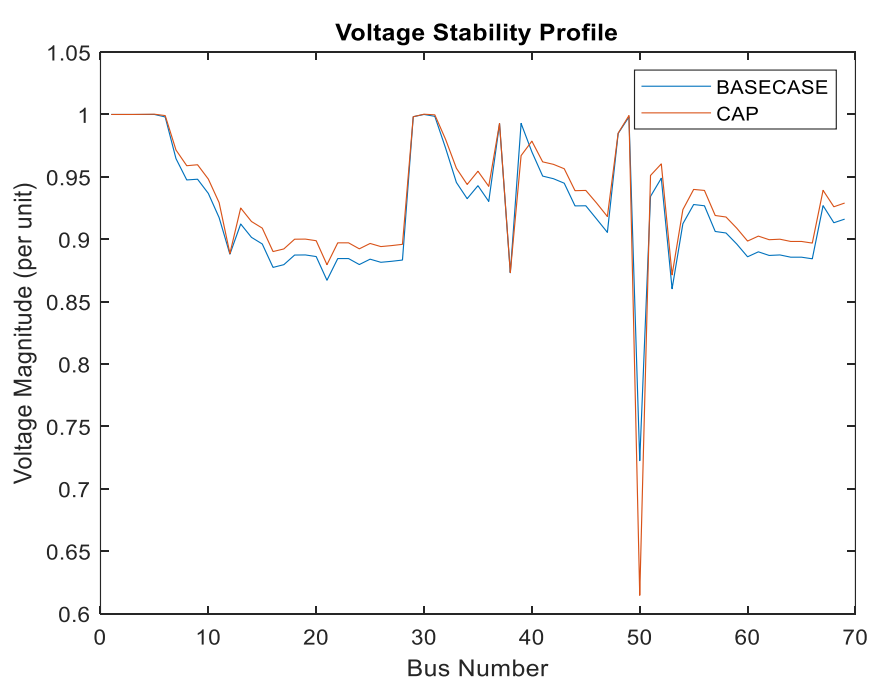

Figure 7: Voltage stability profile for test case 1 for 69 bus system.

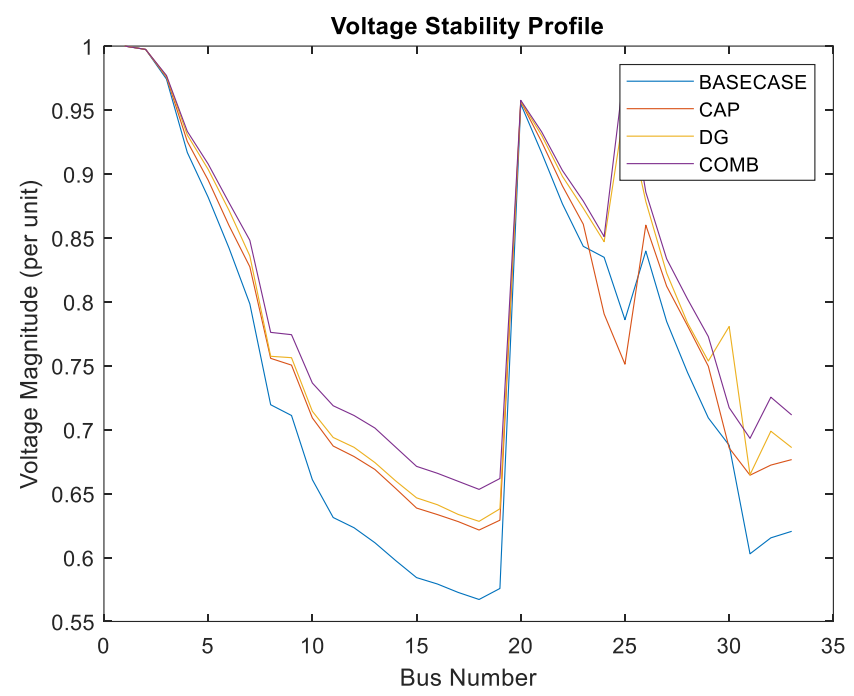

Figure 6: Voltage stability profile for test case 2 for 33 bus system. 


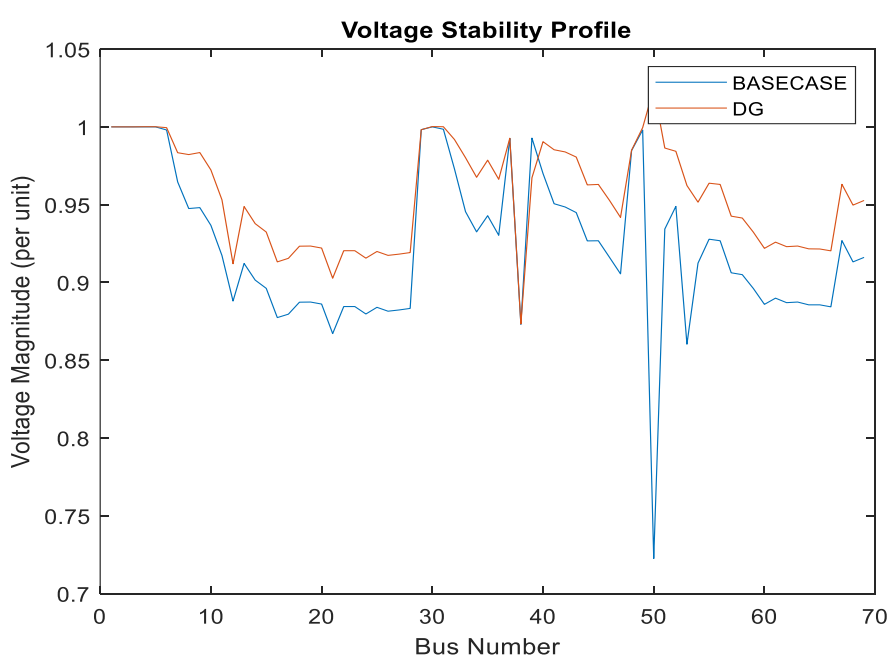

Figure 8: Voltage stability profile for test case $2-69$ bus system.

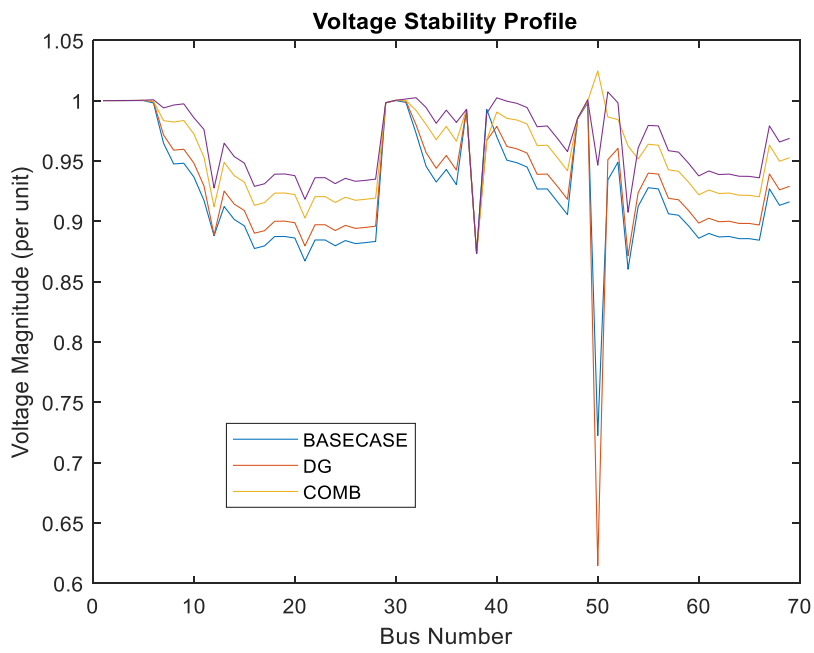

Figure 9: Voltage stability profile for test case $3-69$ bus system.

From Figure $4-9$, the voltage stability profile obtained for test case 1, 2 and 3 for IEEE 33 and 69 bus system shows that there was a significant improvement in voltage stability profile when the test cases were applied to the systems with a significant improvement obtained for test case 3. Power loss (active and reactive) reduction profile for Test case 1, 2 and 3 for IEEE 33 and 69 bus system is also presented in the figures.

\section{3.) Active and reactive power reduction profile for test cases 1,2 and 3}

The active and reactive power loss reduction profiles are presented in Figures 10 - 13, with bar charts for IEEE 33 and 69 bus system. From the bar charts, observation shows a significant reduction in active and reactive power loss when the DG and capacitor bank were simultaneous placed as shown in red when compared to their individual placements.

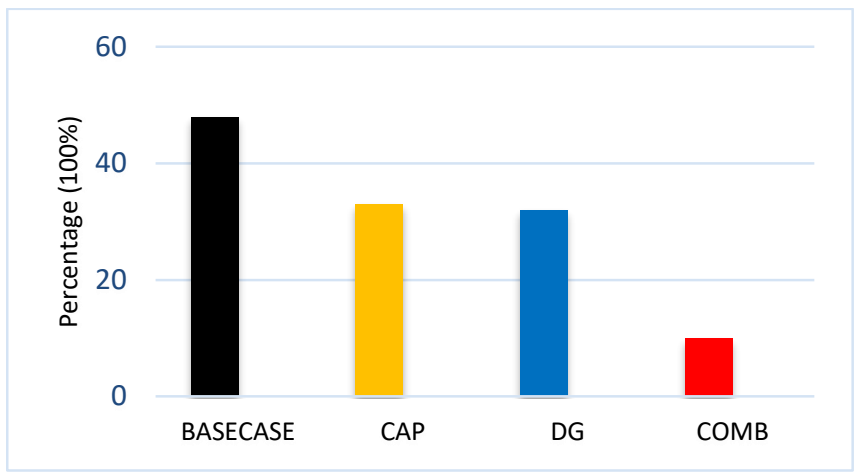

Figure 10: Active power loss reduction profile for 33 -bus system.

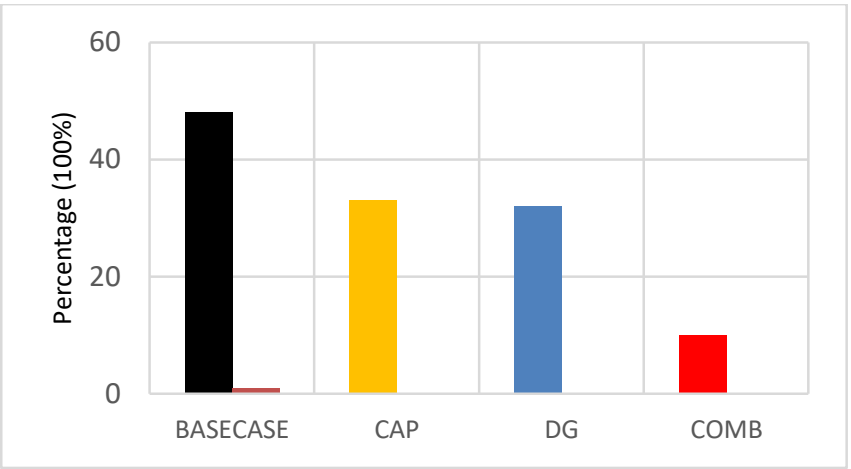

Figure 11: Reactive power loss reduction profile for 33- bus system.

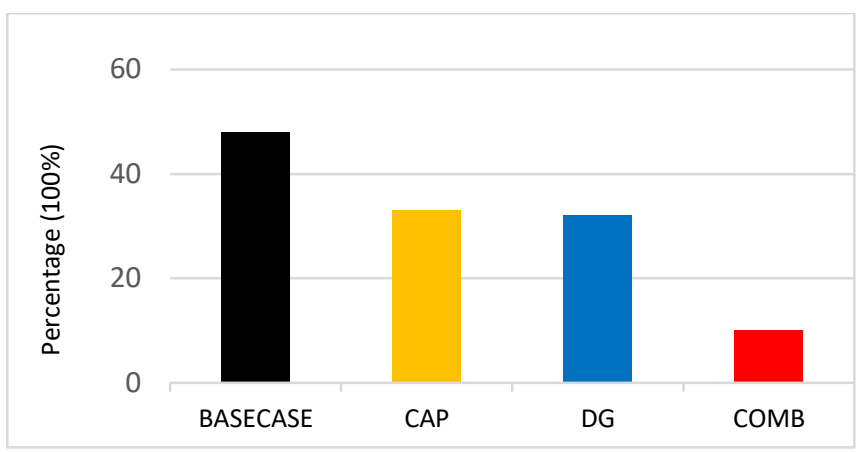

Figure 12: Active power loss reduction profile for 69 -bus system.

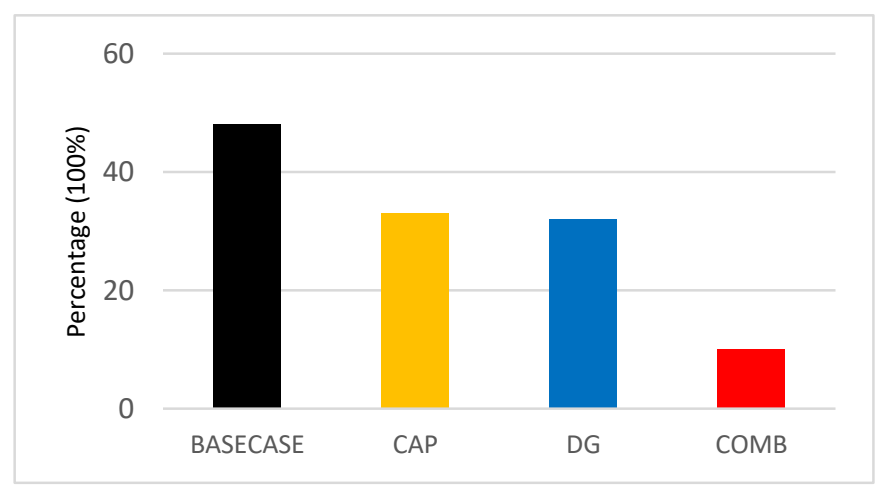

Figure 13: Reactive power loss reduction profile for 69- bus system. 


\section{4.) Voltage improvement profile for test cases 1, 2 and 3}

The voltage improvement profile for IEEE 33 and 69 bus system is presented in figures. Figures $14-19$ shows the pattern of improvement in voltage profile for Test cases 1`, 2 and 3. From the Figures, observation shows that there is improvement in voltage profile when the three test cases where applied to the systems, with a significant improvement obtained with Test case 3, when the DGs and capacitor bank where simultaneously placed.

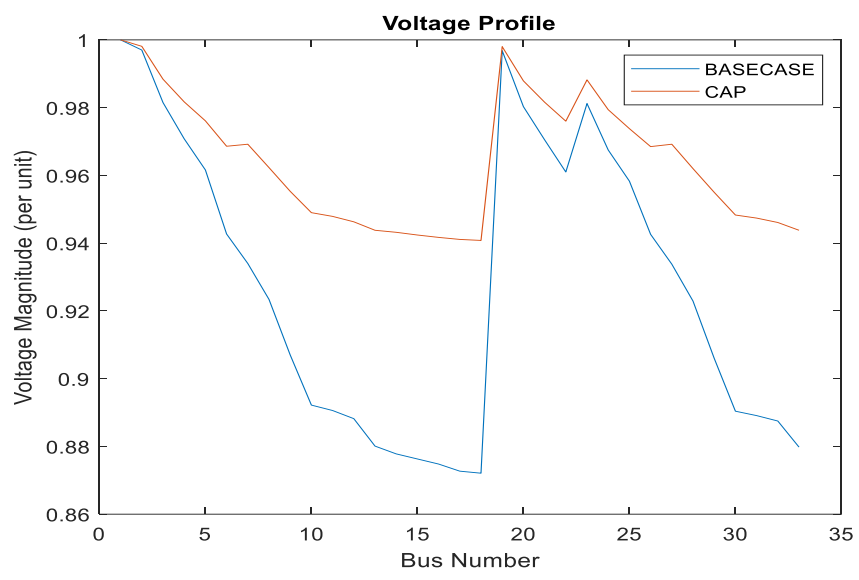

Figure 14: Voltage profile for test case 1 for 33 bus system.

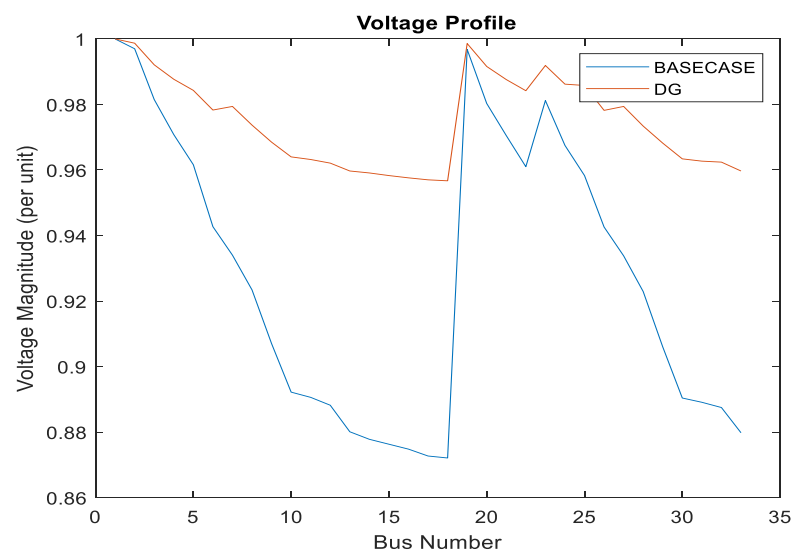

Figure 15: Voltage profile for test case 2 for 33 bus system.

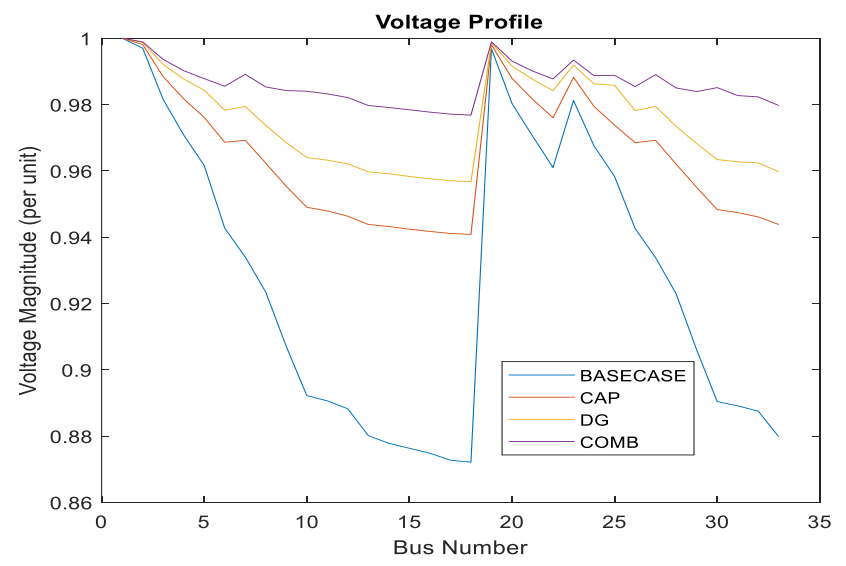

Figure 16: Voltage profile for test case 3 for 33 bus system.

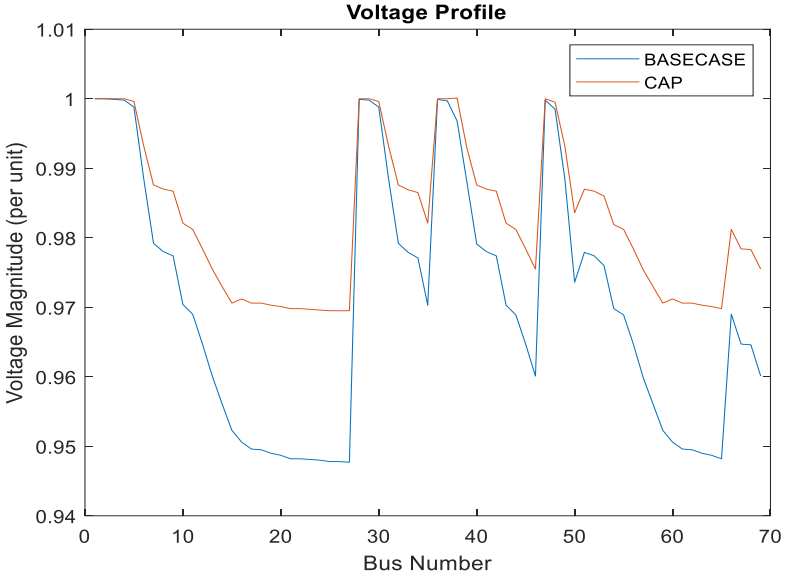

Figure 17: Voltage profile for test case 1 for 69 bus system.

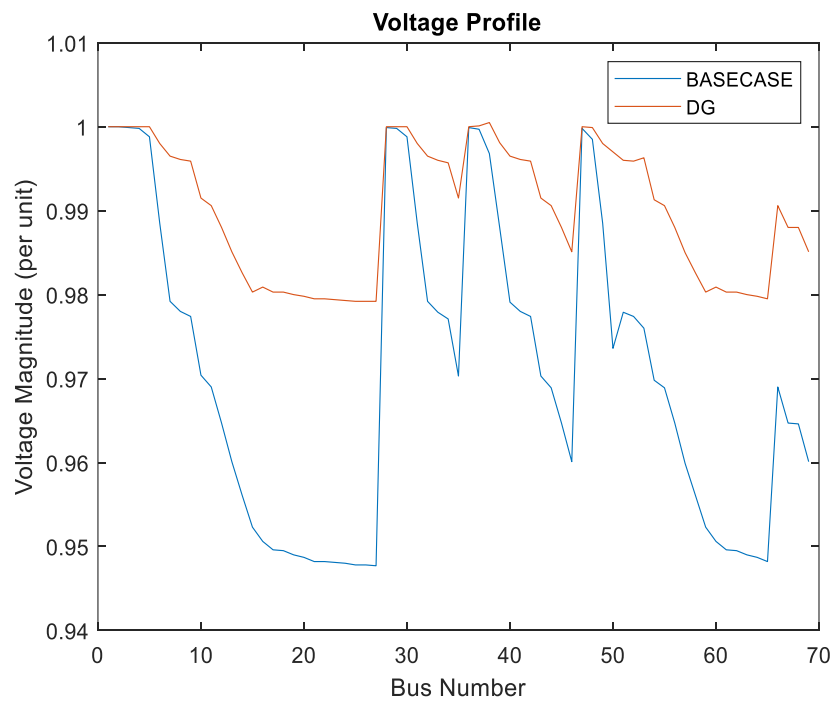

Figure 18: Voltage profile for test case 2 for 69 bus system.

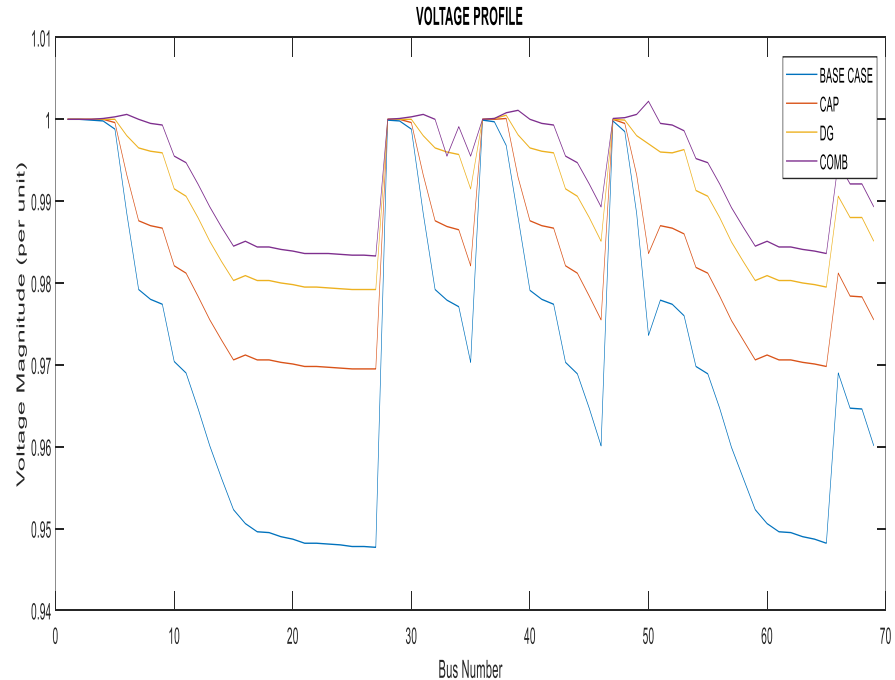

Figure 19: Voltage profile for test case 3 for 69 bus system. 


\section{CONCLUSION}

This research work has the following conclusions;

a) A Cuckoo Search Algorithm has been applied to determine the optimal sizes of distributed generation and shunt capacitor units to be placed on distribution networks.

b) The optimal sizes of distributed generation and shunt capacitor banks results realized from computation when placed individually and simultaneously on the distribution networks shows that power losses (active and reactive) can effectively be reduced to a considerable extent as well as improving the voltage stability profiles of the networks.

c) The Simultaneous distributed generation and shunt capacitor placement approach shows that a better power loss reduction and voltage stability improvement can be obtained as compared to their individual placements and base case values.

\section{REFERENCES}

Ackerman, T; G. Anderson and L. Soder. (2001). Distributed Generation Literature Review", Electric Power System Research, 57(2): 195-204.

Aman, MM; G.B. Jasmon; A.H.A. Bukar and M. Mokhlis. (2013). Optimal Simultaneous DG and Capacitor bank Placement on the Basis of Minimization of Power Losses. IJCEE, 5(5): 516- 522.

Archarya, N; P. Archarya and N. Mithulananthan. (2006). An Analytical Approach for DG Allocation in Primary Distribution Network. International Journal of Electrical Power \& Energy systems, 28(10): 669-678.

Charkravorty, M. and Das, D. (2001). Voltage Stability Analysis of Radial Distribution Networks. International Journal Electrical Power and Energy System, 23(5): 35-129.

El-Khattam, W. and Salama, M.M.A. (2004). Distributed Generation Techniques, Definitions and Benefits. Electrical Power Systems Research, 71(1): 119-128.
Esmaeilian, H.R; O. Darijany and M. Mohammadian. (2014). Optimal Placement and Sizing of DG units and Capacitors Simultaneously in Radial Distribution Networks Based on Voltage Stability Security Margin. Turkish Journal of Electrical Engineering and Computer Science, 5(2): 1-14.

Khodr, H.M; F.G. Olsina and J.M. Yusta. (2008). Maximum Savings Approach for Location and Sizing of Capacitors in Distribution Systems.Electric Power Systems Research, 78(3): 1192- 1203.

Kowsalya, M. (2014). Optimal Distributed Generation and Capacitor Placement in Power Distribution Networks for Power Loss Minimization. International Conference on Advances in Electrical Engineering (ICAEE), 4: 1-5.

Lund, T. (2007). Analysis of Distribution Systems with a high penetration Distributed Generation. PhD. Thesis, Centre for Electric Technology (CET), Technical University of Denmark.

Pepermans, G; J. Driesen; D. Haeseldonckx; R. Belmans and W. Deehaeseleer. (2005). Distributed Generation: Definition, Benefits and issues. Energy Policy, 33(6): 787-798.

Pereira, L. (2004). Cascade to System Blackouts. Power and Energy Magazine IEEE 2(2): 54-57.

Rahiminejad, M; A. Aranizadeh and B. Vahidi. (2014). Simultaneous Distributed Generation and Capacitor Placement and Sizing in Radial Distribution System Considering Reactive Power Market. Journal of Renewable and Sustainable Energy, 6(4): $43-124$.

Sumit, B; C.K. Chanda and S.C. Konar. (2010). Determination of the Weakest Branch in a Radial Distribution System using Reactive Loading. Joint International Conference on Power Electronics Drives and Energy Systems, New Delhi, India, 1-5.

Yang, X.-S. (2010). Cuckoo Search via Levy Flights. World congress on nature and biologically inspired computing (WaBIC), 210-214.

Yuvaraj, T. (2015). D-STATCOM Allocation in Distribution Networks Considering Load variations using Bat Algorithm. Ain Shams Engineering Journal, 8(3): 391-403. 